\title{
Letrozole Therapy versus Extended Clomiphene Citrate Therapy for Induction of Ovulation in Resistant Patients with Polycystic Ovarian Syndrome in Low Resource Communities
}

\author{
Mohamed A. Emara ${ }^{1}$, Dalia I. Mohamed ${ }^{1}$, Mohamed A. M. Hassanein*2, Amira A. Fathey ${ }^{1}$ \\ ${ }^{1}$ Department of Obstetrics and Gynecology, Faculty of Medicine, Menoufia University, Menoufia, Egypt \\ ${ }^{2}$ Department of Obstetrics and Gynecology at Sohag General Hospital, Sohag, Egypt \\ * Corresponding Author: Mohamed Ahmed Mohamed Hassanein, Mobile: 01100121090, \\ E-Mail: mamhassanein@yahoo.com
}

\begin{abstract}
Background: many drugs can be used in ovulation induction in patients with clomiphene-resistant polycystic ovarian syndrome (PCOs).

Objective: to evaluate the effect of letrozole therapy versus extended clomiphene citrate therapy for ovulation induction in clomiphene-resistant polycystic ovarian syndrome patients

Patients and Methods: The study included 100 infertile patients who had failed induction by clomiphene for three cycles. They were randomly allocated to receive either letrozole or extended clomiphene therapy. The effects of these drugs on follicular volume, ovulation, endometrium thickness and occurrence of pregnancy were evaluated. Results: No significant difference was found between both groups regarding age, body mass index, basal FSH level, LH level, prolactin level, thyroid function and semen analysis of the husband. Use of letrozole or extended clomiphene led to improvement of number of growing follicles, ovulation rate and pregnancy rate after 3 cycles of ovulation induction.

Conclusion: The results of this study revealed that use of letrozole or extended treatment with clomiphene did not show better outcomes over each other in number of growing follicles, ovulation rates, occurrence of pregnancy and pregnancy outcomes. Letrozole group showed a significant increase in the endometrium thickness than extended clomiphene group but this did not affect pregnancy rate.
\end{abstract}

Keywords: Letrozole, extend clomiphene therapy, PCOs, clomiphene resistance.

\section{INTRODUCTION}

Polycystic ovarian syndrome (PCOs) is a common endocrinal problem, which estimated that PCOs affects $5 \%$ to $10 \%$ of females between 18 and 44 years old ${ }^{(1)}$. Moreover, PCOs is the commonest cause of anovulation-induced infertility (around 75\% of the cases) ${ }^{(2)}$. The Rotterdam consensus workshop concluded that PCOS is a syndrome of ovarian dysfunction along with the cardinal features of hyperandrogenism and polycystic ovary morphology on ultrasonography ${ }^{(3)}$. PCO patients present with variety of manifestations ${ }^{(4)}$ and many affected patients have decreased fertility due to chronic anovulation ${ }^{(5)}$. Infertility can have direct psychological and social burdens among infertile women, which decreases the life quality for these patients ${ }^{(6)}$.

Clomiphene citrate $(\mathrm{CC})$ is considered to be traditional drug for ovulation induction in PCOs because of its low cost and oral route of administration with limited side effects ${ }^{(7)}$. CC induces ovulation by competing with estrogen (E2) on its receptor in the hypothalamus which prevents the negative feedback effect of estrogen and stimulates the production of follicular stimulating hormone from the pituitary gland that induces ovulation ${ }^{(8)}$. The CC starting dose should be around $50 \mathrm{mg} /$ day for 5 days, starting on day 2 to 5 of menstrual cycle following spontaneous or progestin- induced withdrawal bleeding. The dose can be increased up to $250 \mathrm{mg} /$ day with most effective dose that is between $100-150 \mathrm{mg} /$ day, as ovulation occurs in more than $75 \%$ of cycles treated with these doses. After six to nine cycles of CC therapy, the cumulative pregnancy rates are $70-75 \%{ }^{(9)}$.

Letrozole is a specific aromatase inhibitor that was used to treat patients with breast cancer ${ }^{(10)}$. Letrozole blocks estrogen production from androgen by inhibiting aromatization. By decreasing circulating $\mathrm{E} 2$, the secretion of FSH and luteinizing (LH) hormone increases ${ }^{(11)}$. Letrozole is considered better drug than CC because of its lesser antiestrogenic effect on endometrium ${ }^{(\mathbf{1 2})}$.

There is no specific starting dose for letrozole, however, it is better to start letrozole in low dose (2.5 $\mathrm{mg}$ daily), and the dose is successively increased according to the patient' response ${ }^{(\mathbf{1 3})}$.

About 15 to $40 \%$ of PCOs patients are not responding to ovulation induction by clomiphene therapy. Clomiphene resistant PCOs is defined by ovulation failure after receiving $150 \mathrm{mg}$ /day for 5 days for at least 3 cycles ${ }^{(\mathbf{1 4})}$.

Patients with obesity, insulin resistance and hyperandrogenism are more susceptible for failure of induction by clomiphene; however, presence of clomiphene resistance is unexplainable or unpredictable in most of the cases ${ }^{(\mathbf{8})}$. 


\section{PATIENT AND METHODS}

This prospective comparative study was carried out in the Infertility Clinic in Sohag General Hospital from March 2019 to March 2020 for patients who had failed induction by clomiphene citrate for three cycles.

Ethical approval: The study was approved by the Ethical Committee, Faculty of Medicine, Menofyia University and written informed consent was obtained from all cases. The study included 100 infertile patients.

\section{Inclusion criteria:}

1- Infertile women with patent fallopian tubes proven by hysterosalpingography (HSG), their partner has normal semen parameters according to modified criteria of the World Health Organization (2010).

2- Normal TSH, prolactin and 17-hydroxyprogesterone level.

3- Written consent was obtained from patients after explaining the method and the aim of the study.

\section{Exclusion criteria:}

Women with associated male factor, poor ovarian reserve, tubal factor, endometrial factor and mullarian anomalies by hystosalpingogram. Additionally, associated endocrinal problem as thyroid dysfunction, hyperprolactinemia, congenital adrenal hyperplasia and women with contraindications for pregnancy.

The women included in the study were assessed by comprehensive history taking, body mass index (BMI) and gynecological ultrasound by (Samsung SonoAce R3 Ultrasound with mean frequency of 5 to 7.5 MHz) to evaluate uterus, endometrium, antral follicles count and to exclude presence of uterine anomalies or presence of any ovarian cysts.

The patients were allocated into two groups contained 50 cases each: Group I, received letrozole 5 $\mathrm{mg}$ (Letrozole $2.5 \mathrm{mg}$ ®; Techno Pharma for
Investment and Development, Giza, Egypt) that started from day 3 until day 7 of menstrual cycle. Group II: received $100 \mathrm{mg}$ of clomiphene citrate (Clomid@; Hoechst Marion Russel, Cairo, Egypt) daily starting from day 2 of menses for 10 days.

The mean follicular volume and thickness of the endometrium were assessed on days 7, 9, 11 and up to day 15 of the cycle till one follicle reaches $17 \mathrm{~mm}$.

HCG injection (5000 IU IM) was given when at least one follicle measured at least $17 \mathrm{~mm}$. Patients were advised to have intercourse 24-36 hours after HCG injection. Serum progesterone $(\mathrm{ng} / \mathrm{ml})$ was measured on days 21-23 of the cycle by radioimmunoassay using an antibody-coated tube method (Coat-A-Count; Diagnostic Product Corporation, Los Angeles, CA, USA). Serum pregnancy test was required in the absence of menstruation to diagnose pregnancy.

Outcome measures: Number of growing follicles, mean follicular volume, endometrial thickness, progesterone level, presence of pregnancy.

\section{Statistical analysis}

Results were statistically analyzed by SPSS version 20. Paired t test was used for parametric data. Chi-Squared $\left(\chi^{2}\right)$ test was used for qualitative variables. $\mathrm{P}$ value $\leq 0.05$ is considered significant.

\section{RESULTS}

The study included 100 infertile patients with clomiphene-resistant PCO divided into two groups comprised of 50 patients each, the first one received letrozole for 3 cycles but the second received extended clomiphene therapy for 3 cycles.

There were no significant differences between the two groups regarding the demographic data (age, body mass index and regularity of menstrual cycle) as shown in table (1).

Table (1): Comparison between letrozole group and clomiphene group as regards demographic data

\begin{tabular}{|c|c|c|c|c|c|c|c|}
\hline & & \multicolumn{2}{|c|}{$\begin{array}{l}\text { Letrozole group } \\
(\text { No. }=50)\end{array}$} & \multicolumn{2}{|c|}{$\begin{array}{l}\text { Clomid group } \\
(\text { No. = 50) }\end{array}$} & \multicolumn{2}{|c|}{ Independent $t$ test } \\
\hline & & Mean & SD & Mean & SD & $\mathbf{t}$ & p value \\
\hline \multicolumn{2}{|l|}{ Age (years) } & 24.90 & 2.92 & 25.90 & 2.46 & 1.852 & 0.067 \\
\hline \multirow{2}{*}{\multicolumn{2}{|c|}{ BMI (weight in $\mathrm{kg} /$ height in $\mathrm{m}^{2}$ ) }} & 26.34 & 3.04 & 26.58 & 2.97 & -0.399 & 0.691 \\
\hline & & No & $\%$ & No & $\%$ & \multicolumn{2}{|c|}{ Chi-square } \\
\hline \multirow{3}{*}{$\begin{array}{l}\text { Regularity of } \\
\text { the cycle }\end{array}$} & Amenorrhea & 4 & $8.00 \%$ & 4 & $8.00 \%$ & \multirow[b]{3}{*}{0.047} & \multirow[b]{3}{*}{0.977} \\
\hline & Oligomeonorrhea & 29 & $58.00 \%$ & 30 & $60.00 \%$ & & \\
\hline & Regular & 17 & $34.00 \%$ & 16 & $32.00 \%$ & & \\
\hline
\end{tabular}

BMI: body mass index

In addition, there were no significant differences between the two groups regarding type of infertility, parity and number of abortions (Table 2). 
Table (2): Comparison between letrozole group and clomiphene group as regards infertility, parity and abortion

\begin{tabular}{|c|c|c|c|c|c|c|c|}
\hline & & \multicolumn{2}{|c|}{ Letrozole group $($ No. $=50)$} & \multicolumn{2}{|c|}{ Clomid group $($ No. $=50)$} & \multicolumn{2}{|c|}{ Chi square test } \\
\hline & & No & $\%$ & No & $\%$ & $\mathbf{x}^{2}$ & $\begin{array}{l}\mathbf{p} \\
\text { value }\end{array}$ \\
\hline \multirow{2}{*}{$\begin{array}{l}\text { Infertilit } \\
\mathrm{y}\end{array}$} & Primary & 35 & $70.0 \%$ & 38 & $76.0 \%$ & \multirow{2}{*}{$\begin{array}{l}0.45 \\
7\end{array}$} & \multirow{2}{*}{0.499} \\
\hline & Secondary & 15 & $30.0 \%$ & 12 & $24.0 \%$ & & \\
\hline \multirow{3}{*}{ Parity } & Zero times & 44 & $88.0 \%$ & 44 & $88.0 \%$ & \multirow{3}{*}{$\begin{array}{l}0.00 \\
0\end{array}$} & \multirow{3}{*}{1.000} \\
\hline & One time & 3 & $6.0 \%$ & 3 & $6.0 \%$ & & \\
\hline & Two times & 3 & $6.0 \%$ & 3 & $6.0 \%$ & & \\
\hline \multirow{4}{*}{ Abortion } & Zero times & 38 & $76.0 \%$ & 44 & $88.0 \%$ & \multirow{4}{*}{$\begin{array}{l}5.63 \\
9\end{array}$} & \multirow{4}{*}{0.131} \\
\hline & One time & 6 & $12.0 \%$ & 3 & $6.0 \%$ & & \\
\hline & Two times & 2 & $4.0 \%$ & 3 & $6.0 \%$ & & \\
\hline & $\begin{array}{l}\text { Three } \\
\text { times }\end{array}$ & 4 & $8.0 \%$ & 0 & $0.0 \%$ & & \\
\hline
\end{tabular}

There were no significant differences between the two groups regarding prolactin level, TSH level, hysterosalpingography (HSG) and semen analysis findings (Table 3).

Table (3): Comparison between letrozole group and clomiphene group as regards prolactin, HSG, semen analysis and TSH

\begin{tabular}{|l|l|l|c|c|c|c|c|}
\hline \multirow{2}{*}{} & \multicolumn{2}{|c|}{$\begin{array}{l}\text { Letrozole group } \\
\text { (No. = 50) }\end{array}$} & \multicolumn{2}{c|}{$\begin{array}{l}\text { Clomid group } \\
\text { (No. 50) }\end{array}$} & \multicolumn{2}{c|}{$\begin{array}{l}\text { Chi square test/ } \\
\text { Independent t test* }\end{array}$} \\
\cline { 3 - 8 } & No & $\%$ & No & $\%$ & & $\mathbf{x}^{2} / \mathbf{t}^{*}$ & p value \\
\hline Prolactin & Normal & 50 & $100.0 \%$ & 50 & $100.0 \%$ & NA & NA \\
\hline HSG & Normal & 50 & $100.0 \%$ & 50 & $100.0 \%$ & NA & NA \\
\hline Semen analysis & Normal & 50 & $100.0 \%$ & 50 & $100.0 \%$ & NA & NA \\
\hline TSH & Mean \pm SD & \multicolumn{2}{|c|}{$2.20 \pm 0.771$} & \multicolumn{2}{|c|}{$2.34 \pm 0.86$} & -0.882 & 0.380 \\
\hline
\end{tabular}

HSG: hysterosalpingography TSH: thyroid-stimulating hormone

Basal FSH and LH levels did not show significant differences between the two groups (Table 4).

Table (4): Comparison between letrozole group and clomiphene group as regards basal FSH and basal LH

\begin{tabular}{|l|l|l|l|l|l|l|}
\hline \multirow{2}{*}{} & \multicolumn{2}{|c|}{ Letrozole group (No. = 50) } & \multicolumn{2}{c|}{ Clomid group (No. = 50) } & \multicolumn{2}{c|}{ Independent t test } \\
\cline { 2 - 8 } & Mean & SD & Mean & SD & t & p value \\
\hline Basal FSH & & & & & & \\
& 4.34 & 0.68 & 4.36 & 0.64 & -0.167 & 0.868 \\
\hline Basal LH & 10.43 & 0.84 & 10.67 & 0.83 & -1.435 & 0.155 \\
\hline
\end{tabular}

FSH: follicular stimulating hormone LH: luteinizing hormone

Regarding the first cycle, there were no significant differences between the two groups regarding number of growing follicles, ovulation rates, occurrence of pregnancy and pregnancy outcomes. The endometrium thickness was significantly greater in letrozole group than in extended clomiphene group (Table 5). 
Table (5): Comparison between letrozole group and clomiphene group as regards first cycle

\begin{tabular}{|c|c|c|c|c|c|c|c|}
\hline & & \multicolumn{2}{|c|}{$\begin{array}{l}\text { Letrozole } \\
\text { group } \\
(\text { No. }=\mathbf{5 0}) \\
\end{array}$} & \multicolumn{2}{|c|}{$\begin{array}{l}\text { Clomid } \\
\text { group } \\
(\text { No. = 50) } \\
\end{array}$} & \multicolumn{2}{|c|}{$\begin{array}{l}\text { Chi square test/ } \\
\text { Independent t } \\
\text { test }\end{array}$} \\
\hline & & No & $\%$ & No & $\%$ & $\mathbf{x}^{2} / \mathbf{t}^{*}$ & $\begin{array}{l}\mathbf{p} \\
\text { value }\end{array}$ \\
\hline \multirow{3}{*}{$\begin{array}{l}\text { Number of follicles } \\
\geq 16 \mathrm{~mm}\end{array}$} & Zero & 36 & $72.0 \%$ & 37 & $74.0 \%$ & \multirow{3}{*}{4.680} & \multirow{3}{*}{0.096} \\
\hline & One & 9 & $18.0 \%$ & 3 & $6.0 \%$ & & \\
\hline & Two & 5 & $10.0 \%$ & 10 & $20.0 \%$ & & \\
\hline \multirow{2}{*}{ HCG trigger } & No & 36 & $72.0 \%$ & 37 & $74.0 \%$ & \multirow{2}{*}{0.051} & \multirow{2}{*}{0.822} \\
\hline & Yes & 14 & $28.0 \%$ & 13 & $26.0 \%$ & & \\
\hline Endometrial thickness (mm) & Mean \pm SD & \multicolumn{2}{|c|}{$10.90 \pm 1.90$} & \multicolumn{2}{|c|}{$8.74 \pm 1.82$} & $5.801^{*}$ & $<0.001$ \\
\hline Day 21 Progesterone $(\mathrm{ng} / \mathrm{ml})$ & Mean \pm SD & \multicolumn{2}{|c|}{$7.11 \pm 4.96$} & \multicolumn{2}{|c|}{$7.15 \pm 4.52$} & -0.042 & 0.967 \\
\hline \multirow{2}{*}{ Ovulation rate } & No & 36 & $72.0 \%$ & 37 & $74.0 \%$ & \multirow{2}{*}{0.051} & \multirow{2}{*}{0.822} \\
\hline & Yes & 14 & $28.0 \%$ & 13 & $26.0 \%$ & & \\
\hline \multirow{2}{*}{ Missed period } & No & 44 & $88.0 \%$ & 44 & $88.0 \%$ & \multirow{2}{*}{0.000} & \multirow{2}{*}{1.000} \\
\hline & Yes & 6 & $12.0 \%$ & 6 & $12.0 \%$ & & \\
\hline \multirow{2}{*}{$\begin{array}{l}\text { Pregnancy test after missed } \\
\text { period }\end{array}$} & Negative & 3 & $6.0 \%$ & 3 & $6.0 \%$ & \multirow{2}{*}{6.000} & \multirow{2}{*}{0.112} \\
\hline & Positive & 3 & $6.0 \%$ & 3 & $6.0 \%$ & & \\
\hline \multirow[t]{2}{*}{ Pregnancy outcomes } & $\begin{array}{l}\text { Missed } \\
\text { abortion }\end{array}$ & 0 & $0.0 \%$ & 1 & $2.0 \%$ & \multirow[t]{2}{*}{6.000} & \multirow[t]{2}{*}{0.112} \\
\hline & Positive pulse & & $.0 \%$ & & $.0 \%$ & & \\
\hline
\end{tabular}

*significant HCG: human chorionic gonadotropin

Regarding the second cycle, there were no significant differences among the two groups regarding number of growing follicles, ovulation rates, occurrence of pregnancy and pregnancy outcomes. The endometrium thickness was significantly greater in letrozole group than in extended clomiphene group (Table 6).

Table (6): Comparison between letrozole group and clomiphene group as regards second cycle

\begin{tabular}{|c|c|c|c|c|c|c|c|}
\hline & & \multicolumn{2}{|c|}{$\begin{array}{c}\text { Letrozole group } \\
(\text { No.=47) }\end{array}$} & \multicolumn{2}{|c|}{$\begin{array}{c}\text { Clomid group } \\
(\text { No.=47) }\end{array}$} & \multicolumn{2}{|c|}{$\begin{array}{l}\text { Chi square test/ } \\
\text { Independent } \mathrm{t} \text { test }\end{array}$} \\
\hline & & No & $\%$ & No & $\%$ & $x^{2} / t^{*}$ & p value \\
\hline \multirow{3}{*}{$\begin{array}{c}\text { Number of follicles } \\
\geq 16 \mathrm{~mm}\end{array}$} & Zero & 36 & $76.6 \%$ & 33 & $70.2 \%$ & \multirow{3}{*}{0.507} & \multirow{3}{*}{0.776} \\
\hline & One & 6 & $12.8 \%$ & 8 & $17.0 \%$ & & \\
\hline & Two & 5 & $10.6 \%$ & 6 & $12.8 \%$ & & \\
\hline \multirow[b]{2}{*}{ HCG trigger } & No & 36 & $76.6 \%$ & 33 & $70.2 \%$ & \multirow{2}{*}{0.490} & \multirow[b]{2}{*}{0.783} \\
\hline & Yes & 11 & $23.4 \%$ & 14 & $29.8 \%$ & & \\
\hline Endometrial thickness (mm) & Mean \pm SD & \multicolumn{2}{|c|}{$10.47 \pm 1.83$} & \multicolumn{2}{|c|}{$8.89 \pm 1.41$} & $4.682 *$ & $<0.001$ \\
\hline Day 21 progesterone $(\mathrm{ng} / \mathrm{ml})$ & Mean \pm SD & \multicolumn{2}{|c|}{$6.12 \pm 4.34$} & \multicolumn{2}{|c|}{$6.48 \pm 4.73$} & -0.382 & 0.704 \\
\hline \multirow{2}{*}{ Ovulation rate } & No & 36 & $76.6 \%$ & 33 & $70.2 \%$ & \multirow{2}{*}{0.490} & \multirow{2}{*}{0.783} \\
\hline & Yes & 11 & $23.4 \%$ & 14 & $29.8 \%$ & & \\
\hline \multirow{2}{*}{ Missed period } & No & 44 & $93.6 \%$ & 38 & $80.9 \%$ & \multirow{2}{*}{3.439} & \multirow{2}{*}{0.179} \\
\hline & Yes & 3 & $6.4 \%$ & 9 & $19.1 \%$ & & \\
\hline \multirow{2}{*}{ Pregnancy test after missed period } & Negative & 0 & $0.0 \%$ & 6 & $12.0 \%$ & \multirow{2}{*}{6.409} & \multirow{2}{*}{0.041} \\
\hline & Positive & 3 & $6.4 \%$ & 3 & $6.4 \%$ & & \\
\hline \multirow{2}{*}{ Pregnancy outcomes } & Missed abortion & 1 & $2.1 \%$ & 0 & $0.0 \%$ & \multirow{2}{*}{1.200} & \multirow{2}{*}{0.549} \\
\hline & Positive pulse & 2 & $4.3 \%$ & 3 & $6.4 \%$ & & \\
\hline
\end{tabular}

*significant HCG: human chorionic gonadotropin

Regarding the third cycle, mature follicles were significantly increased in clomiphene group than in letrozole group, while ovulation rates, occurrence of pregnancy and pregnancy outcomes showed no significant differences. The endometrium thickness was significantly greater in letrozole group than in extended clomiphene group (Table 7). 
Table (7): Comparison between letrozole group and clomiphene group as regards third cycle

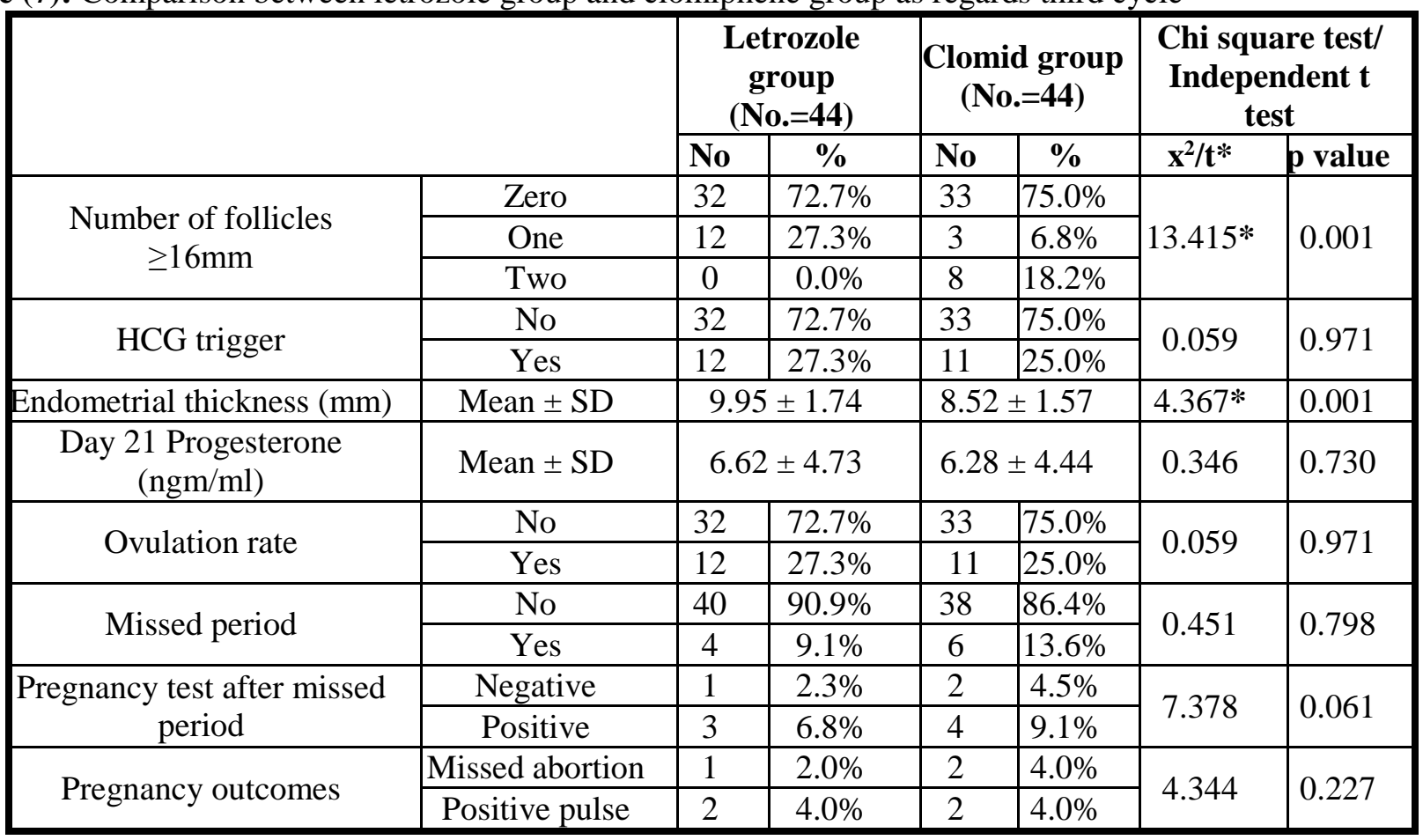

*significant HCG: human chorionic gonadotropin

\section{DISCUSSION}

Comparing the effect of letrozole and clomiphene on ovulation in PCO patients was addressed in many studies $(15,16,17,18,19)$. In some of these studies, higher ovulation rate was reported in patients treated by clomiphene ${ }^{(15,16)}$. Other studies reported higher ovulation rate in women received letrozole in comparison to patients received clomiphene $^{(17,18,19)}$.

This study was performed to compare the effectiveness of letrozole versus extended clomiphene citrate in women with clomiphene resistant PCO and evaluate benefits of these drugs on ovulation induction and achieving pregnancy.

Our study found that ovulation rates in letrozole-treated group were $28 \%, 22 \%$ and $24 \%$ in first, second and third cycles respectively. They were not statistically significant form extended clomiphene group where they were $26 \%, 28 \%$ and $22 \%$ in first, second and third cycles respectively. These results are consistent with Badawy et al. ${ }^{(20)}$ and Bayar et al. ${ }^{\text {(21) }}$ who found a comparable ovulation rates between letrozole and clomiphene. Other studies showed higher ovulation rates among patients received letrozole in comparison with patients received clomiphene ${ }^{(17,18,22)}$. Five-day clomiphene therapy was used in these studies. Therefore, the higher ovulation rates that detected in our study may be due to the use of extended clomiphene therapy.

The number of mature ovarian follicles (greater than $16 \mathrm{~mm}$ ) during the third followed cycle was significantly higher in women received clomiphene than in those received letrozole, but it was comparable between both groups in first and second cycles. Multifolliculogenesis was reported to be higher after ovulation induction by clomiphene than letrozole ${ }^{(20)}$. Mono-folliculogenesis of letrozole is a consequence of smaller rise in the follicular phase FSH, which is shorter in duration compared to clomiphene ${ }^{(\mathbf{1 6})}$.

In our study, statistically significant increase was reported in endometrial thickness in patients received letrozole compared to those received clomiphene. Compared with clomiphene, letrozole doesn't have negative effects on cervix mucus and has no antiestrogenic effects on the endometrium, which contributes to a better chance of implantation and pregnancy as well ${ }^{(23)}$. Many studies showed that women treated with letrozole had a better endometrium thickness in comparison with women received clomiphene $(\mathbf{1 6}, \mathbf{2 4}, \mathbf{2 5})$ or clomiphene and metformin ${ }^{(22)}$.

The effectiveness of these drugs to achieve pregnancy was studied. The chemical and clinical indicators of pregnancy and abortions were not significantly different between clomiphene-resistant patients in the letrozole and clomiphene groups. These findings are comparable to the results of Liu et al. ${ }^{(18)}$ who reported no significant difference in the pregnancy rate, abortion rate, and live birth rate in women with PCOS who received letrozole or clomiphene. In a systematic review and meta-analysis on patients with unexplained infertility treated with letrozole compared to clomiphene citrate, there were no significant differences in pregnancy test $(24 \%$ vs $23 \%$ ), clinical pregnancy, live birth, spontaneous 
miscarriage, or twin gestation (23). Other studies concluded that treatment with letrozole was associated with a higher pregnancy rates in comparison with clomiphene ${ }^{(26)}$. In a recent Cochrane review, showed that use of letrozole in PCOS patients was associated with higher pregnancy rates than clomiphene citrate. There are little or no differences in rates of miscarriage and multiple pregnancies (27). However, all these studies did not use an extended clomiphene therapy and experienced a higher significant rate of ovulation in letrozole groups than clomiphene groups, which may be the reason for decreasing pregnancy rate.

\section{CONCLUSION}

Our study showed comparable effectiveness of letrozole and extended clomiphene therapy in the treatment of clomiphene-resistant PCOS. Extended clomiphene therapy, compared to letrozole, was associated with an equal ovulation rates, pregnancy rate and pregnancy outcome.

\section{REFERENCES}

1. March W, Moore V, Willson $\mathrm{K}$ et al. (2010): The prevalence of polycystic ovary syndrome in a community sample assessed under contrasting diagnostic criteria. Hum Reprod., 25 (2): 544-51.

2. Sirmans S, Pate K (2013): Epidemiology, diagnosis, and management of polycystic ovary syndrome. Clin Epidemiol., 6: $1-13$

3. Bart C (2004): Revised 2003 consensus on diagnostic criteria and long-term health risks related to polycystic ovary syndrome. Fertil Steril., 97 (1): 28-38.

4. McFarland C (2012): Treating polycystic ovary syndrome and infertility. Am J Matern Child Nurs., 37 (2): 116-21.

5. ACOG practice bulletin (2009): Polycystic ovary syndrome. Obstet. Gynecol., 114 (4): 936-49.

6. Hasanpoor-Azghdy S, Simbar M, Vedadhir A (2014): The emotional-psychological consequences of infertility among infertile women seeking treatment: Results of a qualitative study. Iran J Reprod Med., 12 (2): 131-8.

7. Fauser B, Tarlatzis B, Rebar R et al. (2012): Consensus on women's health aspects of polycystic ovary syndrome (PCOS): the Amsterdam ESHRE/ASRM-Sponsored 3rd PCOS Consensus Workshop Group. Fertil Steril., 97(1):2838.

8. Imani B, Eijkemans M, Velde E et al. (1998): Predictors of Patients Remaining Anovulatory during Clomiphene Citrate Induction of Ovulation in Normogonadotropic Oligoamenorrheic Infertility. J Clin Endocrinol Metab., 83 (7): 2361-5.

9. Tarlatzis B, Fauser B, Legro R et al. (2008): Consensus on infertility treatment related to polycystic ovary syndrome: The Thessaloniki ESHRE-ASRM-Sponsored PCOS Consensus Working Group. Fertil Steril., 89 (3): 505-22.

10. He D, Ma X (2016): Clinical utility of Letrozole in the treatment of breast cancer: A Chinese perspective. Onco Targets Ther., 9: 1077-1084.

11. Kar K (2012): Clomiphene citrate or letrozole as first-line ovulation induction drug in infertile PCOS women: A prospective randomized trial. J Hum Reprod Sci., 5 (3): 262-
265.

12. Al-Omari W, Sulaiman W, Al-Hadithi N (2004): Comparison of two aromatase inhibitors in women with clomiphene-resistant polycystic ovary syndrome. Int $\mathbf{J}$ Gynecol Obstet., 85 (3): 289-91.

13. Guang H, Li F, Shi J (2018): Letrozole for patients with polycystic ovary syndrome. Medicine (Baltimore), 97 (44): e13038.

14. Brown J, Farquhar C, Beck J et al. (2009): Clomiphene and anti-oestrogens for ovulation induction in PCOS. Cochrane Database Syst Rev., 7 (4): CD002249.

15. Al-Obaidi M, Ali Z, AL-Saadi W et al. (2019): Impact of letrozole versus clomiphene citrate on endometrial receptivity in Iraqi women with polycystic ovarian syndrome. J Clin Pharm Ther., 44 (4): 618-622.

16. Palihawadana T, Wijesinghe $P$, Seneviratne $H$ (2015): A comparison of endometrial thickness following augmentation of ovulation with clomifene citrate or letrozole in women with ovulatory infertility. Ceylon Med., 60 (2): 4852.

17. Legro R, Brzyski R, Diamond M et al. (2014): Letrozole versus clomiphene for infertility in the polycystic ovary syndrome. N Engl J Med., 371 (2): 119-129.

18. Liu C, Feng G, Huang W et al. (2017): Comparison of clomiphene citrate and letrozole for ovulation induction in women with polycystic ovary syndrome: a prospective randomized trial. Gynecol Endocrinol., 33 (11): 872-876.

19. Hu S, Yu Q, Wang Y et al. (2018): Letrozole versus clomiphene citrate in polycystic ovary syndrome: a metaanalysis of randomized controlled trials. Arch of Gynecol Obstet., 297 (5): 1081-10881.

20. Badawy A, Abdel Aal I, Abulatta M (2009): Clomiphene citrate or letrozole for ovulation induction in women with polycystic ovarian syndrome: a prospective randomized trial. Fertil Steril., 92 (3): 849-852.

21. Requena A, Herrero J, Landeras J et al. (2008): Use of letrozole in assisted reproduction: a systematic review and meta-analysis. Hum Reprod Update, 14 (6): 571-582.

22. Rezk M, Shaheen A, Saif El-Nasr I (2018): Clomiphene citrate combined with metformin versus letrozole for induction of ovulation in clomiphene-resistant polycystic ovary syndrome: a randomized clinical trial. Gynecol Endocrinol., 34 (4): 298-300.

23. Eskew A, Bedrick B, Hardi A et al. (2019): Letrozole compared with clomiphene citrate for unexplained infertility: A systematic review and meta-analysis. Obstet Gynecol., 133 (3): 437-444.

24. Wang L, Wen X, Lv S et al. (2019): Comparison of endometrial receptivity of clomiphene citrate versus letrozole in women with polycystic ovary syndrome: a randomized controlled study. Gynecol Endocrinol., 35 (10): 862-865.

25. Najafi P, Noghabi S, Afzali $N$ et al. (2020): Comparing the effect of clomiphene citrate and letrozole on ovulation induction in infertile women with polycystic ovary syndrome. J Pak Med Assoc., 70 (2): 268-271.

26. Amer S, Smith J, Mahran A et al. (2017): Double-blind randomized controlled trial of letrozole versus clomiphene citrate in subfertile women with polycystic ovarian syndrome. Hum Reprod., 32 (8): 1631-1638.

27. Franik S, Eltrop S, Kremer J et al. (2018): Aromatase inhibitors (letrozole) for subfertile women with polycystic ovary syndrome. Cochrane Database Syst Rev., 5 (5): CD010287. 